NASA Technical Memorandum 100246

\title{
Wear of Iron and Nickel in Corrosive Liquid Environments
}

(NASA-TM-100246) WEAR OF IRON AND NICKEL IN
CORROSIVE LIQUID ENVIRONMENTS
(NASA) $20 . p$
AVII: NTIS HC A03/MF AOT

N88-11817

$\begin{array}{ll}\text { G3 } 3 / 26 & \text { Unclas } \\ 0107556\end{array}$

Kazuhisa Miyoshi

Lewis Research Center

Cleveland, Ohio

and

George W.P. Rengstorff

The University of Toledo

Toledo, Ohio

Prepared for the

Corrosion ' 88

sponsored by the National Association of Corrosion Engineers

St. Louis, Missouri, March 21-25, 1988 
WEAR OF IRON AND NICKEL IN CORROSIVE LIQUID ENVIRONMENTS

\author{
Kazuhisa Mi yoshi \\ National Aeronautics and Space Administration \\ Lewis Research Center \\ Cleveland, Ohio 44135 \\ George W.P. Rengstorff* \\ The University of Toledo \\ Department of Chemical Engineering \\ Toledo, Ohio 43606
}

\begin{abstract}
SUMMARY
An investigation was conducted to examine the friction and wear behavior of iron and nickel sliding on aluminum oxide in aerated sulfuric acid and hydrochloric acid. The results indicate that the concentration of acid is an important factor in controlling the metal loss caused by wear-corrosion processes in the acids. At very dilute acid concentration $\left(10^{-4} \mathrm{~N}\right)$, iron behaves differently than nickel. Iron develops a soft, friable deposit, while nickel develops no corrosion layer. The formation and removal of the corrosion deposit on iron resulted in high metal loss and coefficient of friction, as compared to the relatively low metal loss and coefficient of friction observed for nickel. At slightly higher acid concentration $\left(10^{-3}\right.$ and $\left.10^{-2} \mathrm{~N}\right)$, no corrosion products were produced on both iron and nickel. Wear of iron and nickel was generally at a minimum. At higher acid concentration $\left(10^{-1} \mathrm{~N}\right.$ and above), loss of iron and nickel increased as the acid concentration increased. In sulfuric acid the maximum loss of both iron and nickel was at $7.5 \mathrm{~N}$ (30 percent) concentration, and the metal losses of both iron and nickel dropped markedly at $15 \mathrm{~N}$ (50 percent) and above. In hydrochloric acid, however, the iron loss continued to increase with the increase of acid concentration, and the maximum iron loss occurred in the most concentrated acid (12.1 N, 37 percent). There were variations in loss with nickel from specimen to specimen examined in concentrated hydrochloric acids $\left(10^{-1} \mathrm{~N}\right.$ and above). The coefficient of friction for iron decreased with increasing concentration of both acids. The coefficient of friction for nickel increased slightly with an increase in acid concentration up to $10^{-2} \mathrm{~N}$. When corrosion started to dominate in the wearcorrosion process, the coefficient of friction decreased in both sulfuric and hydrochloric acids at $10^{-1} \mathrm{~N}$ and above.
\end{abstract}

\title{
INTRODUCTION
}

Corrosion and wear of aerospace bearings are serious, expensive, and major problems (refs. 1 to 3 ). Bearings tend to fail at random intervals from corrosion, contamination, wear, or handling damage long before fatigue initiates spaliing. Corrosion accounts for nearly one-third of the bearing rejections from their aircraft systems, including drivelines, wheels, and accessories at a U.S. Naval Air Rework Facility (ref. 2). Air Force experience also confirms corrosion to be a major cause of rejection of aircraft turbine engine bearings (ref. 3).

*Emeritus Professor. 
Cryogenic turbopump bearings in current and future rocket engines, such as the space shuttle main engine, also require the use of much improved corrosion and wear resistant bearings without a tradeoff in material durability (ref. 1).

Considerable work is being conducted on the development of new alloys, surface modification techniques (such as ion implantation and coatings), and corrosion-inhibited lubricants which will extend the operating life of a bearing closer to its ultimate fatigue capability. 3 Most of these studies have been concerned with specific practical problems. Although several attempts have been made to study the basic mechanisms governing triboelectrochemical effects on the wear-corrosion phenomena of metals, its role is not well understood (refs. 4 and 5).

In the sliding, rolling, or rubbing contact of materials the surfaces become strained as a result of the mechanical activity that takes place. A wear surface is different electrochemically from its surroundings. It contains metal that is highly strained and that reaches high temperatures locally at shearing points or asperities (refs. 6 and 7 ). Electrochemical potentials may be established locally to either impede or enhance corrosion; cyclic stresses may promote stress corrosion and corrosive fatigue (ref. 8).

Resistance to corrosion is often the result of the formation of some type of film on the metal. Sliding action can destroy such films, or it can develop better corrosion-resistant films by producing new surfaces. The coefficient of friction is, like corrosion resistance, highly sensitive to surface films.

The objective of this paper is to examine the interfacial friction and wear of elemental iron and nickel exposed to sulfuric acid and hydrochloric acid in water at various concentrations as well as to water. Their surface chemistry and morphology were examined by $x$-ray photoelectron spectroscopy (XPS), optical microscopy, and scanning electron microscopy (SEM). Aluminum oxide (sapphire) has been considered for use in contact with iron and nickel,

because it has greater wear and corrosion-resistance than metals. Some earlier publications on this research are given in references 9 to 14 .

\section{MATERIALS}

The iron used in this investigation was better than 99.99 percent pure and was annealed to a hardness of 30 to 35 Rockwell B after machining.

The electrolytic nickel was annealed to a Rockwell B hardness of 30 after machining.

The sapphire flats were single-crystal aluminum oxide. The sulfuric acid was ACS reagent-grade concentrated acid, which is specified to be 95.5 to 96.5 percent acid by weight; it is referred to herein as 96 percent. The hydrochloric acid was ACS reagent grade concentrated acid ( 37 percent $\mathrm{HCl}$ by weight). The water used by itself in the experiments and used in making the solutions was deionized, distilled, and subsequently saturated with air at room temperature. 


\section{APPARATUS}

The apparatus used in this investigation is shown schematically in figures 1 and 2 . The specimen rider was made to traverse a distance of $10 \mathrm{~mm}$ on the surface of the aluminum oxide flat. Motion was reciprocal. The rider was loaded against the flat with a dead weight. The arm retaining the rider contained strain gauges to measure the tangential force (i.e., friction force). The entire apparatus was housed in a plastic box.

\section{EXPERIMENTAL PROCEDURE}

Hemispherical tips $(3.2 \mathrm{~mm}$ radii) of the iron and nickel riders were polished with 6- and 3-um diamond paste. Final polishing was conducted with a wet metallographic polishing cloth impregnated with $0.3-\mu m$ alpha-aluminum oxide. The rider specimens were rotated in a lathe for the polishing operation. Afterward, the polished riders were rinsed with absolute ethyl alcohol, using a cotton swab to help remove the polishing powder.

The aluminum oxide flats placed in their cups (fig. 2) were mounted in the jig. The iron or nickel riders were lowered to a few millimeters above the flats, and alignments were checked. Then the acid or water was dropped into the cups to cover the flats to the proper depth. Thereafter, the riders were lowered until the tips just contacted the flat surfaces. The weight was then loaded onto the rider and sliding begun. Under an applied load the friction force was sensed by the strain gauges and continuously monitored during a wear experiment. All the coefficients of friction reported in this paper are kinetic values. All the wear experiments were conducted with the iron and nickel riders in sliding contact with the aluminum oxide flats at $1.5 \mathrm{~mm} / \mathrm{sec}$ at a load of $2.5 \mathrm{~N}$ in laboratory air at room temperature. Each experiment was conducted for $60 \mathrm{~min}$. Thus, the rider passed over the track 540 times (270 times each way in reciprocal motion) during an experiment.

The amount of metal lost in wear was determined by measuring the size of the wear spot (wear scar) on the tip after an experiment. The wear spot was photographed at a nominal magnification of 100 . The maximum length of the wear spot, occurred in the direction of motion, and the minimum length of the wear spot were measured on the photographic print. These were converted to true size using the correct magnification as determined by calibration. Then the amount of metal that would have been removed with a circular spot of the minimum length of the observed spot was calculated. The same calculation was made asssuming that the wear spot had a diameter equal to its longer dimension. The two volumes were averaged to give an estimate of the amount of metal lost during the experiment. The volumes were calculated using the equation (ref. 15):

$$
V=\frac{\pi}{3}\left[2 R^{3}-\left(2 R^{2}+r^{2}\right) \sqrt{\left(R^{2}-r^{2}\right)}\right]
$$

where

$R$ radius of the hemispherical rider

$r$ radius of the circular spot 


\section{RESULTS AND DISCUSSION}

\section{Sulfuric Acid}

Friction and wear experiments were conducted with iron and nickel riders in contact with aluminum oxide flats in aerated sulfuric acid with concentrations ranging from dilute $\left(7 \times 10^{-5} \mathrm{~N}, 4 \mathrm{ppm}\right)$ to concentrated $(35.6 \mathrm{~N}$, 96 percent) at a load of $2.5 \mathrm{~N}$ for $60 \mathrm{~min}$. In dilute solutions, $\mathrm{pH}$ is an inverse function of hydrogen ion concentration, so increasingly low or negative pH is associated with sulfuric acid up to about 30 percent acid (refs. 11 to 13). At higher concentrations, the hydrogen ion concentration decreases, while $\mathrm{pH}$ increases again.

Iron. - It is well known that iron usually corrodes rapidly in nonoxidizing acids. However, if the oxidation is strong enough, the iron surface may become passivated by a protective oxide layer. Corrosion behavior of iron in sulfuric acid is consistent with this generality (ref. 13).

Figure 3 presents the friction and wear data for iron riders in contact with aluminum oxide flats in aerated sulfuric acid. At the very dilute sulfuric acid concentrations of $7 \times 10^{-5}$ to $2 \times 10^{-4} \mathrm{~N}$ (4 to $12 \mathrm{ppm}$ ), both friction and wear were highly variable (fig. 3). In the very dilute acid, a complex surface deposit formed on the surface of iron. It is recognized as a mixture of divalent and trivalent iron hydroxides, iron oxides, iron oxyhydroxides (refs. 16 to 20). There was also $x$-ray photoelectron spectroscopic evidence that iron sulfate was part of the built-up layer (ref. 9). This deposit was weak and friable and was not a protective, passivating film. A thick oxidation product formed in the wear area was cracked extensively by interfacial sliding action. Some of the deposit broke away from the wear area and appeared as wear debris. Thus, formation and failure of the hydroxide-oxideoxyhydroxide-sulfate deposit gave erratic and often relatively high friction and great loss of iron in the wear area. The build-up of the corrosion product was not only limited to the wear area, but also occurred in the region well outside the wear area (ref. 13).

At slightly higher sulfuric acid concentrations $\left(10^{-3}\right.$ to $10^{-1} \mathrm{~N}, 0.005$ to 0.5 percent), the loss of metal in the wear area was at a minimum, and there was little evidence of build-up of corrosion products on the wear area and outside it, when they were examined by using optical and scanning electron microscopy. The scanning electron photomicrographs of the iron riders revealed grain boundary etching outside the wear area (ref. 13).

When $\mathrm{pH}$ is high enough at some high concentrations (60 to 96 percent), an oxide film continuous enough to passivate the iron will not readily dissolve. Below 60 percent sulfuric acid, the corrosion rates of iron are relatively high. The published results of iron corrosion rates at 25 and 50 percent sulfuric acid are over a thousand times that at 75 percent (ref. 19).

Metal losses in the wear area increased sharply from the value at $1.0 \mathrm{~N}$ ( 5 percent) acid to a maximum at $7.5 \mathrm{~N}$ (30 percent) acid (fig. 3). The maximum metal loss occurred with iron in $7.5 \mathrm{~N}$ (30 percent) sulfuric acid. The great metal loss at $7.5 \mathrm{~N}$ sulfuric acid is due to the known high corrosion rate of iron (ref. 16). However, this effect dropped markedly in 15 N (50 percent) sulfuric acid but not to the very low value in the dilute $\left(10^{-3}\right.$ to 
$10^{-1} \mathrm{~N}$ ) acids. The high corrosion rate still greatly affects the metal losses during wear experiments at 23 (75 percent) and $35.6 \mathrm{~N}$ (96 percent) acid. The relatively high metal losses at high concentrations of acid ( 50 to 96 percent) suggested that sliding action removed the passivating film and established a galvanic cell between the wear area and its surroundings.

There were no significant differences between the appearance of wear areas and surrounding areas for sulfuric acid concentrations ranging from $1.0 \mathrm{~N}$ to $35.6 \mathrm{~N}$ (5 to 96 percent). Grain boundary etching occurred even in the wear area where plastic flow caused by sliding action tends to smear the surface. But corrosion did not produce faceted corrosion patterns as in the wear areas of nickel corroded under similar conditions, as will be described later. However, the iron surface outside the wear area indicated a faceted, rapid corrosion pattern.

The coefficient of friction gradually decreased with increasing the acid concentration ( $f i g .3(b)$ ).

Nickel. - Table 1 shows the published corrosion rates of nickel in aerated sulfuric acid over most of the concentration range (ref. 21).

Figure 4 presents the friction and wear data for nickel riders in contact with aluminum oxide flats in aerated sulfuric acids. The lowest loss of nickel induced by the wear-corrosion process occurred at $10^{-4} \mathrm{~N}$ (5 ppm), which is the most dilute acid examined. Scanning electron microscopic examination of the wear scar indicated that the nickel was not attacked by this dilute acid in the wear area or outside (ref. 12). Furthermore, no corrosion product formed on the wear surface.

In $10^{-3}$ and $10^{-2} \mathrm{~N}$ sulfuric acid the metal loss was as $10 \mathrm{w}$ as at $10^{-4} \mathrm{~N}$, while the coefficient of friction was a little higher. However, optical and scanning electron microscopic examination revealed that the wear scar and some of its surroundings are different from those at $10^{-4} \mathrm{~N}$ acid (ref. 12).

Although there was little evidence of bulld-up of corrosion products and corrosion pattern in the wear area, corrosion patterns resulting from fluid erosioncorrosion action were observed just outside the wear scar in the direction of the reciprocal sliding motion. Note that this erosion-corrosion effect was not observed well outside the wear scar $(100 \mu \mathrm{m}$ or more). The surface well outside the wear scar has an uncorroded structure. Thus, metal was predominantly lost by mechanical wear rather than corrosion in the dilute $10^{-4}$ to $10^{-2} \mathrm{~N}$ sulfuric acid.

For the sulfuric acid concentration of $10^{-1} \mathrm{~N}$, the amount of metal lost in the wear-corrosion process was three times the loss in the dilute acid at $10^{-2} \mathrm{~N}$ or less. Scanning electron microscopic examination revealed uneven surface structures of the wear scar: one was smooth, and the other was irregular and faceted due to corrosion. It might be anticipated from this examination that much more active corrosion could occur at $1.0 \mathrm{~N}$ or more concentrated acid.

In $1.0 \mathrm{~N}$ (5 percent) sulfuric acid metal loss in the wear scar was 7 or 8 times greater than the loss in $10^{-2} \mathrm{~N}$ or less. Optical and scanning electron microscopic examination indicated that corrosion of nickel inside the wear area was rapid enough to give a strongly faceted corrosion surface, while that outside the wear area was low. The great difference in corrosion rates inside 
and outside the wear scar is caused by the wear-induced removal of a protective surface film produced on the nickel and the establishment of a galvanic cell between the wear scar and its surroundings. The wear scar became the anode where nickel rapidly dissolved and lost; the surroundings became the cathode and were not corroded greatly.

The amount of metal lost in the wear area, which had started to rise at approximately $10^{-1} \mathrm{~N}(0.5$ percent) sulfuric acid, continued to increase as the concentration increased to $7.5 \mathrm{~N}$ (30 percent). Between 7.5 and $15 \mathrm{~N}$ ( 30 and 50 percent) acid concentration, metal lost in the wear area dropped to $30 \times 10^{-5} \mathrm{~mm}^{3}$, which is not much different from the $26 \times 10^{-5} \mathrm{~mm}^{3}$ observed for $10^{-1} \mathrm{~N}(0.5$ percent). At 21,25 , and $35.5 \mathrm{~N}(65,75$, and 96 percent) acid concentration the wear dropped further, but did not reach the low values in the dilute acid at $10^{-2}, 10^{-3}$, and $10^{-4} \mathrm{~N}$ concentrations.

Scanning electron microscopic examination indicated both strongly faceted corrosion area and relatively smooth worn areas developed in the interior of the wear scar at 7.5 and $15 \mathrm{~N}$ (30 and 50 percent) acid concentration. There was, however, greater corrosion attack inside the wear area at $7.5 \mathrm{~N}$ (30 percent) acid concentration than that at $15 \mathrm{~N}$ (50 percent). Thus, corrosion has greatly enhanced overall deterioration; likewise, wear greatly enhanced the corrosion in the sulfuric acid at $10^{-1}$ to $7.5 \mathrm{~N}(0.5$ to 30 percent) acid concentration.

A relatively smooth worn surface was observed by optical and scanning electron microscopic examination throughout the wear scar at 21 to $35.5 \mathrm{~N}$ (65 to 96 percent) acid concentrations (ref. 12). There were no rough, highly corroded areas in the wear scar. It appeared that passivation or polarization layers are being formed on nickel almost as fast as they can be worn away. Thus, the passivating films were formed fast enough to protect even wear areas in the sulfuric acids at 21,25 , and $35.5 \mathrm{~N}(65,75$, and 96 percent) concentrations.

The coefficient of friction was slightly increased with increasing the acid concentration to $10^{-2} \mathrm{~N}$. When corrosion dominated in the wear-corrosion process, the coefficient of friction started to decrease in the sulfuric acid at $10^{-1} \mathrm{~N}$ and above.

\section{Hydrochloric Acid}

Friction and wear experiments were conducted with iron and nickel riders in contact with aluminum oxide flats in aerated hydrochloric acid with concentrations ranging from dilute $\left(10^{-4} \mathrm{~N}, 0.0004\right.$ percent) to fully concentrated ( $12.1 \mathrm{~N}, 37$ percent) for iron and to highly concentrated ( $6 \mathrm{~N}, 20$ percent) for nickel at a load of $2.5 \mathrm{~N}$ for $60 \mathrm{~min}$.

Iron. - Figure 5 presents the friction and wear data for iron riders in contact with aluminum oxide flats in aerated hydrochloric acid. Optical and scanning electron microscopic examination revealed a thick build-up of oxidation products in the wear scar of iron rider in the most dilute acid $\left(10^{-4} \mathrm{~N}\right)$. 
The wear and coefficient of friction in the dilute hydrochloric acid at $10^{-4} \mathrm{~N}$ concentration were slightly higher than those in water or in $10^{-3} \mathrm{~N}$ acid, just as they were in the dilute sulfuric acid described earlier. The higher friction and wear are caused by the build-up and break-up of oxidation products on the surface of iron riders. Thus, iron develops a complex corrosion product layer over the entire immersed surface, particularly thick in the wear scar of the iron rider in the most dilute acid. This deposit was weak and friable and was not a protective, passivating film. Some of the deposits were cracked by interfacial sliding action and broke away from the wear scar and appeared as wear debris.

At $10^{-3} \mathrm{~N}$ hydrochloric acid concentration, the wear and coefficient of friction were lowered. There was little metal loss from corrosion, and the corrosion product was not formed on the iron rider. The metal losses were essentially caused by mechanical wear.

Between $10^{-2}$ and $12.1 \mathrm{~N}(0.04$ and 37 percent) hydrochloric acid concentration, the wear area has become susceptable to corrosion. Optical and scanning electron micrographic examination indicated that the higher the hydrochloric acid concentration, the greater the corrosion of iron observed. Metal loss increased progressively with increasing acid concentration in agreement with the scanning electron microscopic observation and the literature on static corrosion (ref. 19). The maximum metal loss occurred in the most concentrated $12.1 \mathrm{~N}$ (37 percent) acid.

Figure 6 presents an optical photomicrograph and scanning electron photomicrographs of a wear scar, generated by the wear-corrosion process in the most concentrated hydrochloric acid (12.1 N, 37 percent). It becomes obvious from figure $6(a)$ that iron was heavily corroded over the region outside the wear scar. Iron corrosion is predominant in the dark areas of the wear scar. These latter areas are areas where iron was heavily and deeply corroded. On the other hand, mechanical wear of iron is evident and predominant in the light area of the wear scar. This is the area where the surfaces of iron and aluminum oxide were mechanically interacting together.

Details of the dark and light areas in the wear scar and of the regions outside the wear scar are presented in figures $6(b)$ to (d), respectively. Figure $6(b)$ reveals the relatively rough and corroded fracture surfaces in the wear scar. Shear fracture occurred at very local areas in the iron during repeated sliding. The fracture surfaces were then corroded. The regions outside the wear scar presented in figures $6(c)$ and $(d)$ reveal evidence of extensive corrosion. Figure $6(d)$ indicates the comparatively smooth corrosion patterns of iron produced by corrosion along with a fracture-pit generated mechanically.

The coefficient of friction gradually decreased with increasing acid concentration ( $f$ ig. $5(b)$ ).

Nickel. - Figure 7 presents the friction and wear data for nickel riders in contact with aluminum oxide flats in aearated hydrochloric acid. At the 
low acid concentration of $10^{-4} \mathrm{~N}$, there is an anomalously high wear and corrosion loss of nickel which has not been explained.

The metal losses in $10^{-3}$ and $10^{-2} \mathrm{~N}$ hydrochloric acid were relatively low. Scanning electron microscopic examination of the nickel rider worn in $10^{-3} \mathrm{~N}$ hydrochloric acid indicated that the wear area was very smooth. Neither the wear area nor the region outside the wear scar show any evidence of corrosion. Thus, corrosion did not contribute to wear loss in water and in the dilute hydrochloric acids of $10^{-4}$ to $10^{-2} \mathrm{~N}$.

At hydrochloric acid concentrations ranging from $10^{-1}$ to $12.1 \mathrm{~N}(0.4$ to 20 percent), metal losses became very erratic from specimen to specimen, as presented in figure 7 . In addition to the large variations of metal losses, the metal losses were also greater than those in the dilute acids at $10^{-4}$ to $10^{-2} \mathrm{~N}$ concentration.

Optical and scanning electron microscopic examination indicated that there were variations in morphology of wear surfaces even under identically same experimental conditions. For example, figures 8 and 9 present the surface morphology of two nickel riders worn in $10^{-1} \mathrm{~N}$ hydrochloric acid under identical experimental conditions. The rider presented in figure 8 had only approximately one-third the metal loss of the rider in figure 9 . The optical photomicrographs in figures $8(a)$ and $9(a)$ revealed light and dark regions in the wear scars, but the proportion of light region is less in figure $8(a)$ which had less metal loss. The light regions were relatively smoother than the dark regions in the wear scars. A careful examination of the scanning electron micrographs of these regions reveals that plastic flow occurs in the light regions and extensive corrosion and severe mechanical wear occurs in the dark regions with repeated sliding.

Figure $8(b)$ shows both plastically deformed area and corroded area. Figure $8(c)$ also reveals extensive corrosion in the wear scar.

Figure $9(b)$ reveals that plastic flow, observed in the region near the center of the wear scar, occurs in the nickel. Figure $g(c)$ shows that the light rim inside the wear area was relatively very smooth. It was similar to the wear surface of the nickel worn in $10^{-3} \mathrm{~N}$ hydrochloric acid. Figure $9(\mathrm{~d})$ reveals evidence of wear damages, which were generated at local spots. Shear fracture occurs at very local areas in the nickel during repeated sliding.

Although the nickel specimen was cleaned with ethyl alcohol and dried after the wear experiment, there were some wear debris particles and oxide deposits on the nickel surfaces. For example, figure $9(e)$ illustrates a detailed examination of the oxide wear debris (submicrometer to micrometers in size) deposited at the edge of the wear scar. Figure 9 (e) also reveals that plastic flow occurs in the wear scar in the nickel and the nickel outside the wear scar appears to be lightly attacked by corrosion. The lightly corroded surface outside the wear scar contained etch pits and grooves. The elastic and plastic strain energy at regions of surface damage such as scratches produced during mechanical polishing with diamond powder can cause chemical attack during the wear-corrosion process. The etch pits and grooves correspond to defects developed during the mechanical polishing process. 
The variation in morphology of wear surfaces and the amount of loss of nickel at acid concentrations ranging from $10^{-1}$ to $12.1 \mathrm{~N}$ may be associated with the well-known sensitivity of the corrosion rate of nickel to dissolved oxygen in hydrochloric acid. Corrosion and wear of nickel in hydrochloric acid are sensitive to the amount of aeration (ref. 20). When corrosion dominates in the wear-corrosion process, nickel loss and coefficient of friction are low. On the other hand, when mechanical wear dominates in the wearcorrosion process, nickel loss and coefficient of friction are high.

The coefficient of friction was slightly increased with increasing the acid concentration to $10^{-2} \mathrm{~N}(\mathrm{fig} .7(\mathrm{~b}))$. When corrosion dominated in the wear-corrosion process, the coefficient of friction started to decrease in the hydrochloric acid at $10^{-1} \mathrm{~N}$ and above.

\section{CONCLUSIONS}

The following conclusions were drawn from the data presented herein on the tribological characteristics of iron and nickel in sulfuric acid, hydrochloric acid, and water.

The concentration of acid is an important factor in controlling the metal loss caused by wear-corrosion processes in sulfuric acid and in hydrochloric acid.

At very dilute acid concentration $\left(10^{-4} \mathrm{~N}\right)$, iron behaves differently than nickel. Iron develops a soft, friable deposit, while nickel develops no corrosion layer. The formation and removal of the corrosion deposit on iron resulted in high metal loss and coefficient of friction, as compared to the relatively low metal loss and coefficient of friction observed for nickel.

At slightly higher acid concentration $\left(10^{-3}\right.$ and $\left.10^{-2} \mathrm{~N}\right)$, no corrosion products were built up on both iron and nickel. Iron and nickel loss were generally at a minimum.

At higher acid concentrations $\left(10^{-1} \mathrm{~N}\right.$ or above), loss of metals increased as the acid concentration increased. In sulfuric acid the maximum loss of both iron and nickel was at $7.5 \mathrm{~N}$ (30 percent) concentration, and the loss of iron and nickel dropped markedly at $15 \mathrm{~N}$ (50 percent) and above. In hydrochloric acid, however, the iron loss continued to increase with the increase in acid concentration and the maximum iron loss occurred in the most concentrated acid ( $12.1 \mathrm{~N}, 37$ percent). Although the nickel loss increased with the increase in hydrochloric acid concentration, the variation in metal loss from specimen to specimen also increased with the nickel examined in concentrated hydrochloric acids $\left(10^{-1} \mathrm{~N}\right.$ and above).

The coefficient of friction for iron decreased with an increase in concentration of both sulfuric acid and hydrochloric acid. The coefficient of friction for nickel slightly increased with increasing the acid concentration up to $10^{-2} \mathrm{~N}$. When corrosion started to dominate in the wear-corrosion process, the coefficient of friction decreased in both sulfuric acid and hydrochloric acid at $10^{-1} \mathrm{~N}$ and above. 


\section{REFERENCES}

1. R.J. Parker and E.N. Bamberger. Lubrication Engineering, Vol. 40, p. 299 (1984).

2. J.S. Cunningham Jr. and M.A. Morgan. Lubrication Engineering, Vol. 35, p. 435 (1979).

3. H.F. Jones. Lubrication Engineering, Vol. 35, p. 441 (1979).

4. S. Bhattacharyya, V.S. Agaarwala, and K.Y. Kim. Wear of Materials 1985, (ed., K.C. Ludema) ASME, pp. 162-172 (1985).

5. T.S. Eyre. Source Book on Wear Control Technology. (eds., D.A. Rigney and W.A. Glaeser) American Society for Metals, pp. 1-10 (1978).

6. F.P. Bowden and D. Tabor. The Friction and Lubrication of Solids, Clarendon Press, Oxford, Vol. 2 (1964).

7. E. Rabinowicz. Friction and Wear of Materials, John Wiley and Sons, Inc., (1965).

8. R.W. Staehle. Materials Science and Engineering, Vol. 25, p. 207 (1976).

9. G.W.P. Rengstorff, K. Miyoshi, and D.H. Buckley. Friction and Wear of Iron in Corrosive Media, NASA TP-1985 (1982).

10. G.W.P. Rengstorff, K. Miyoshi, and D.H. Buckley. ASLE Transactions, Vol. 26, p. 509 (1983).

11. G.W.P. Rengstorff, K. Miyoshi, and D.H. Buckley. Friction and Wear of Iron in Sulfuric Acid, NASA TP-2289 (1983).

12. G.W.P. Rengstorff, K. Miyoshi, and D.H. Buckley. Friction and Wear of Nickel in Sulfuric Acid, NASA TP-2290 (1984).

13. G.W.P. Rengstorff, K. Miyoshi, and D.H. Buckley. ASLE Transactions, Vol. 29, p. $43(1986)$.

14. K. Miyoshi, D.H. Buckley, G.W.P. Rengstorff, and H. Ishigaki. Industrial and Engineering Chemistry - Product Research and Development, Vol. 24, p. 425 (1985).

15. R.S. Burington. Mathematical Tables and Formulas, Handbook of Chemistry, Sixth Ed., Handbook Publishers, Inc., (1946) M 14.

16. M.G. Fontana and N.D. Greene. Corrosion Engineering, Second Ed., McGrawHill Book Co. (1978).

17. H.H. Uhlig. Corrosion and Corrosion Control, Second Ed., John Wiley and Sons, (1971).

18. M.J.N. Pourbaix. Atlas of Electrochemical Equilibria in Aqueous Solutions, Second English Ed., National Association of Corrosion Engineers, (1974). 
19. N.D. Tomashov. Theory of Corrosion and Protection of Metals, Translated and edited by B.H. Tytell, I. Geld, and H.S. Preiser, Macmillan, (1966).

20. K. Hauffe. Oxidation of Metals, Plenum Press, New York, (1965).

21. Producers Handbook; Huntington Alloys, Resistance to Corrosion, The International Nickel Co., Inc., 1965, revised 1970.

TABLE I. - CORROSION TESTS

OF N ICKEL I N AERATED

$S U L F U R$ I C ACI D A T

$303 K\left(86^{\circ} \mathrm{F}\right)(\mathrm{REF} .21)$

\begin{tabular}{|c|c|}
\hline $\begin{array}{c}\text { ACID } \\
\text { CONCENTRATION, } \\
\text { WT } \%\end{array}$ & $\begin{array}{c}\text { CORROSION RATE, } \\
\text { MM/YR }\end{array}$ \\
\hline 1 & 1.2 \\
5 & 1.5 \\
50 & .4 \\
93 & .3 \\
\hline
\end{tabular}




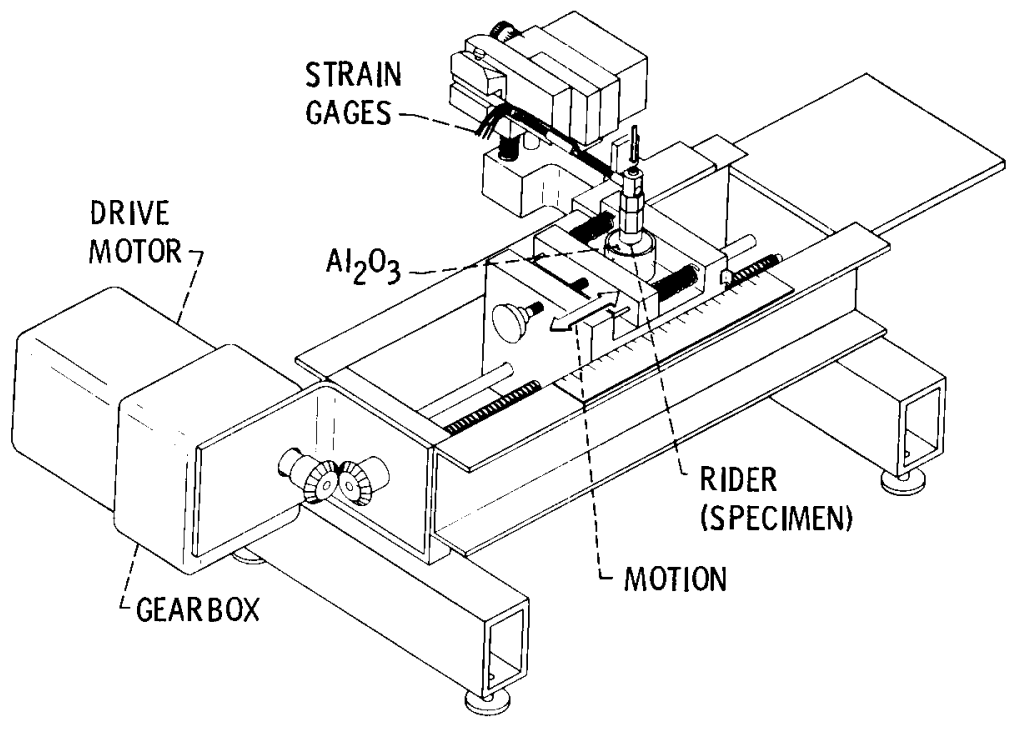

FIGURE 1. - FRICTION AND WEAR APPARATUS.

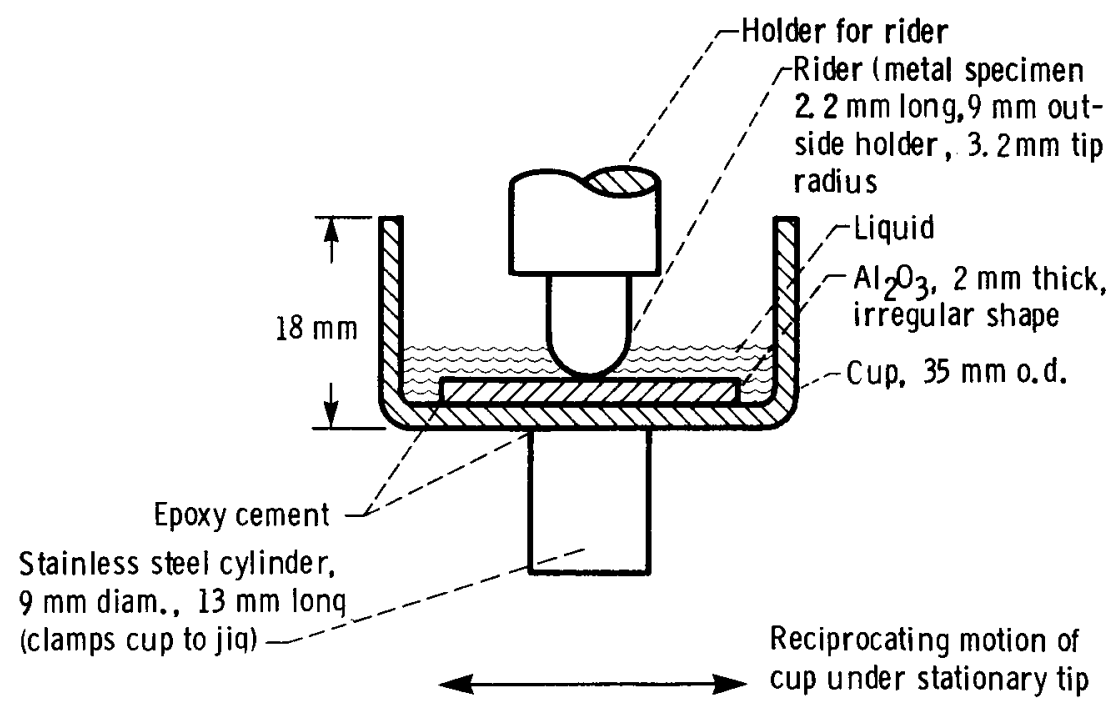

FIGURE 2. - DETAILS OF RIDER, $\mathrm{Al}_{2} \mathrm{0}_{3}$ SURFACE, AND CUP FOR LIQUID. 


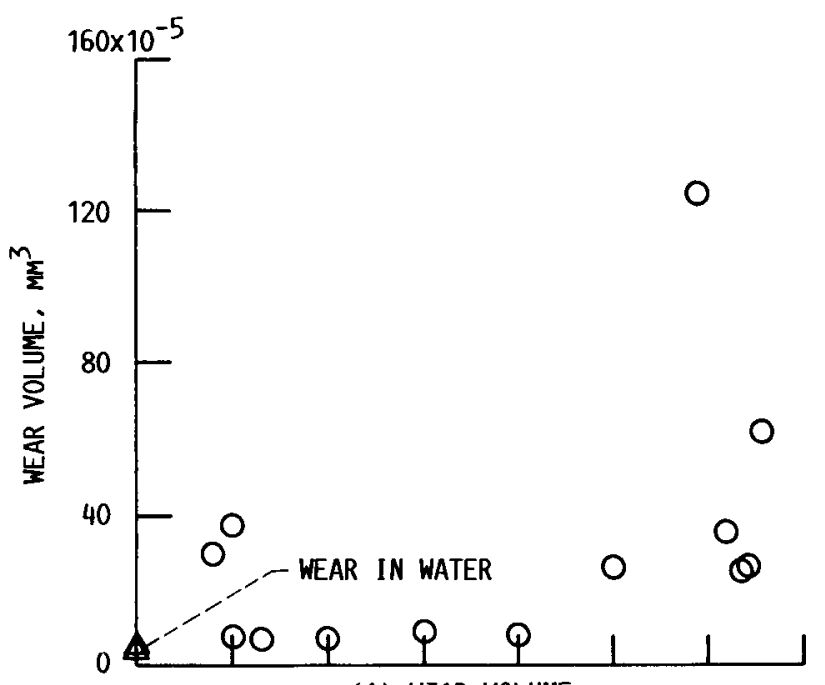

(A) WEAR VOLUME.

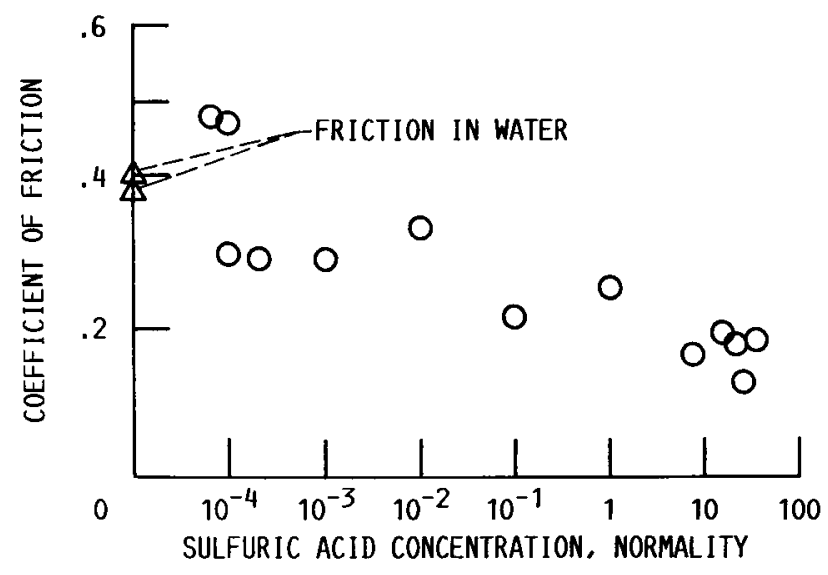

(B) COEFFICIENT OF FRICTION.

FIGURE 3. - WEAR AND COEFFICIENT OF FRICTION FOR IRON AS FUNCTION OF SULFURIC ACID CONCENTRATION.
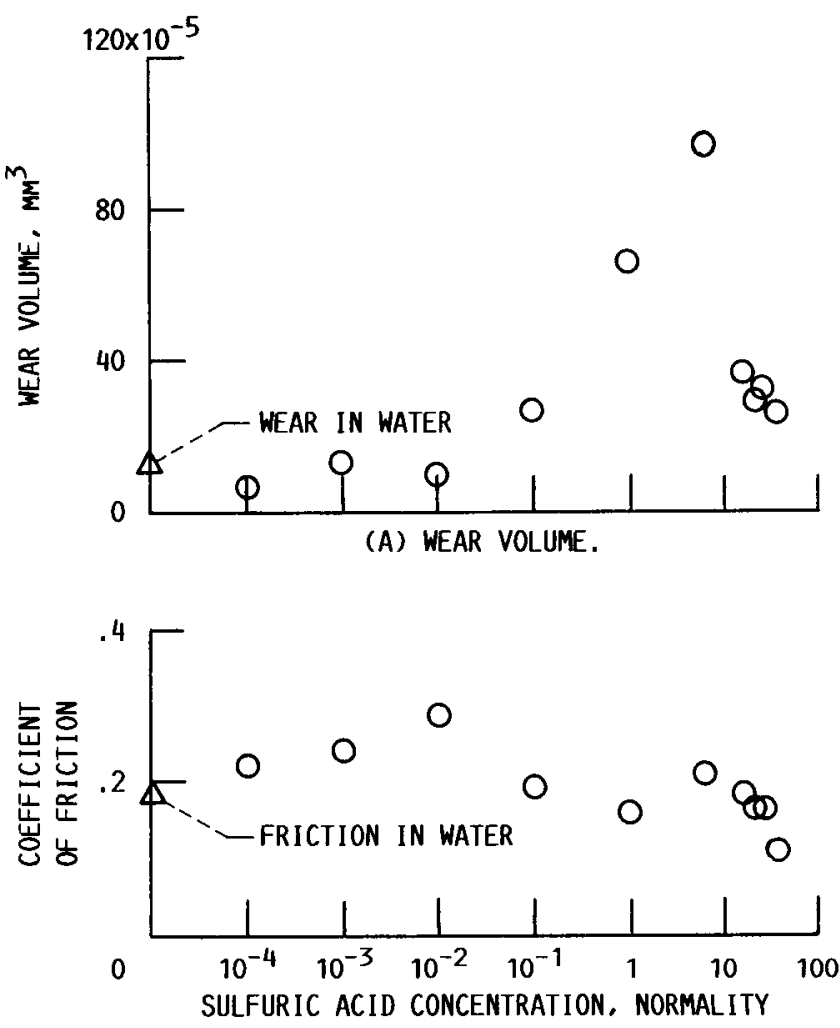
(B) COEFFICIENT OF FRICTION.

FIGURE 4. - WEAR AND COEFFICIENT OF FRICTION FOR NICKEL AS FUNCTION OF SULFURIC ACID CONCENTRATION. 

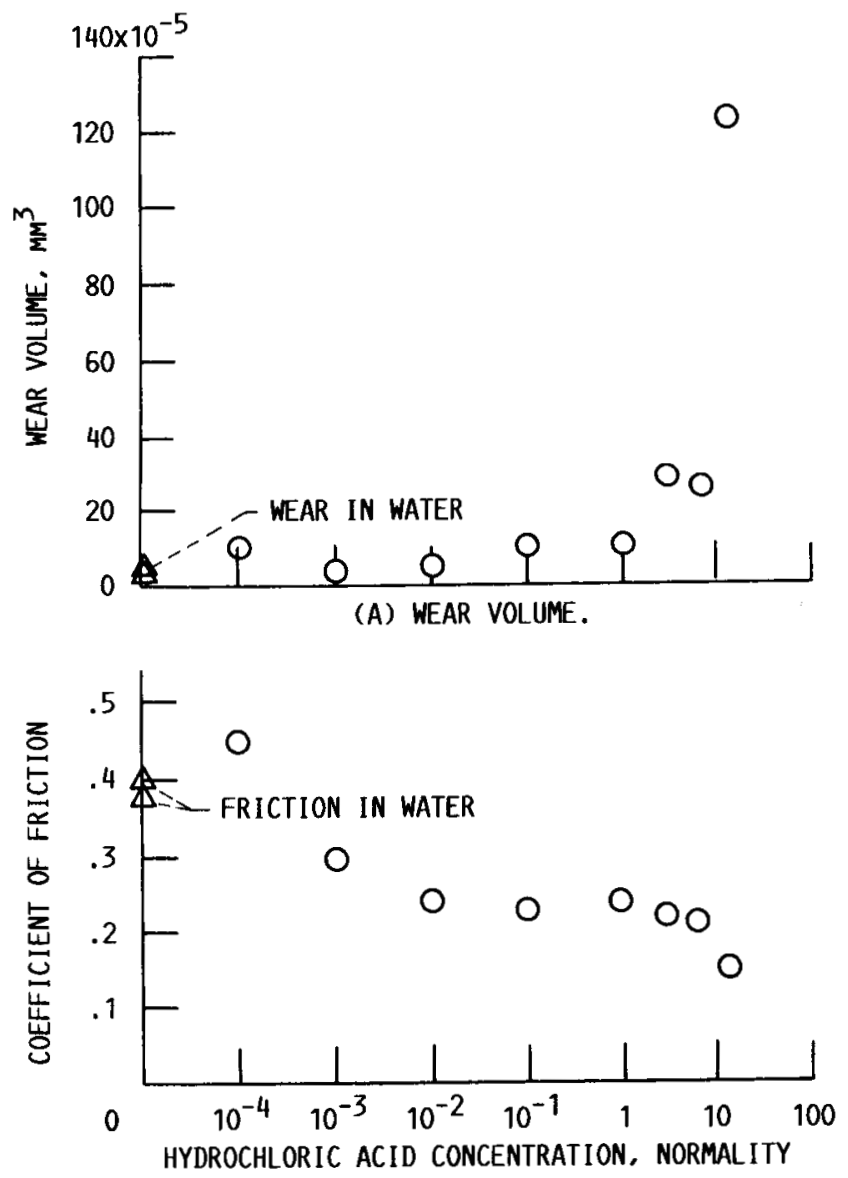

(B) COEFFICIENT OF FRICTION.

FIGURE 5. - WEAR AND COEFFICIENT OF FRICTION FOR IRON AS FUNCTION OF HYDROCHLORIC ACID CONCENTRATION. 


\section{ORIGINAI PAGE IS \\ OE POOR QUALITY}

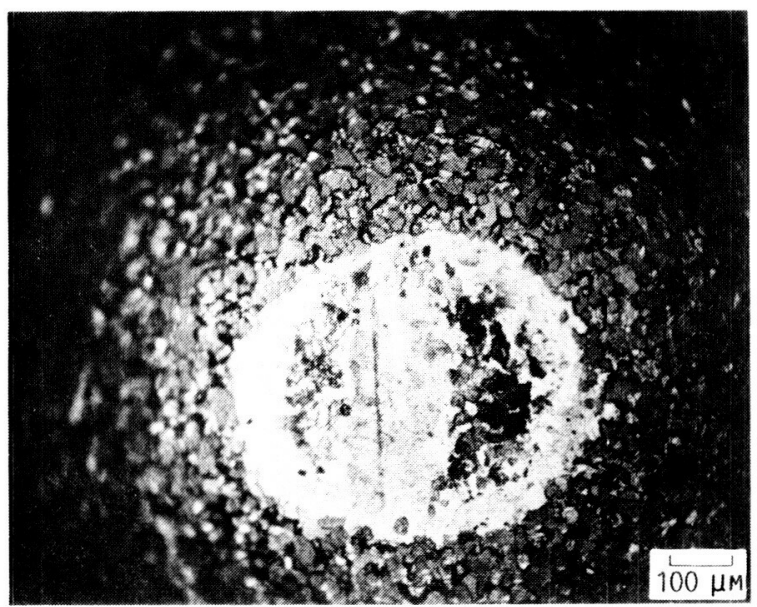

(A) WEAR SCAR.

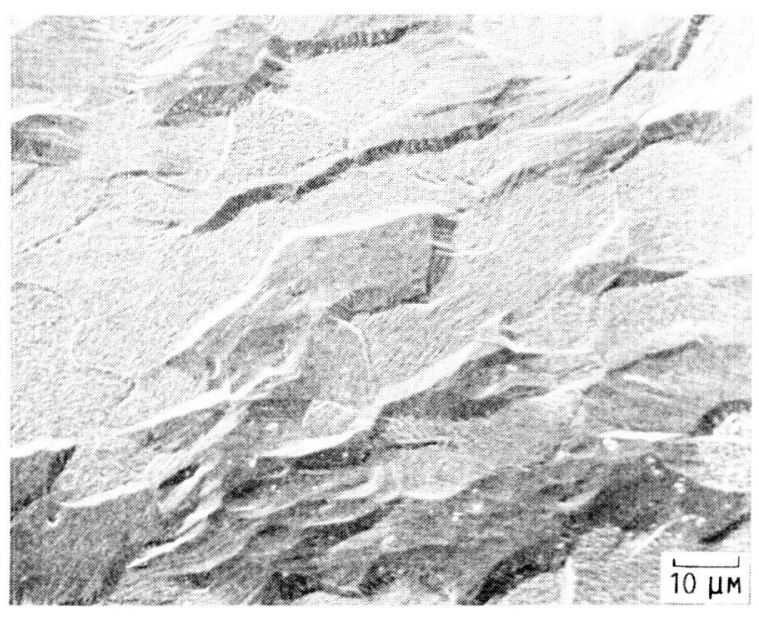

(C) REGION OUTSIDE WEAR AREA.

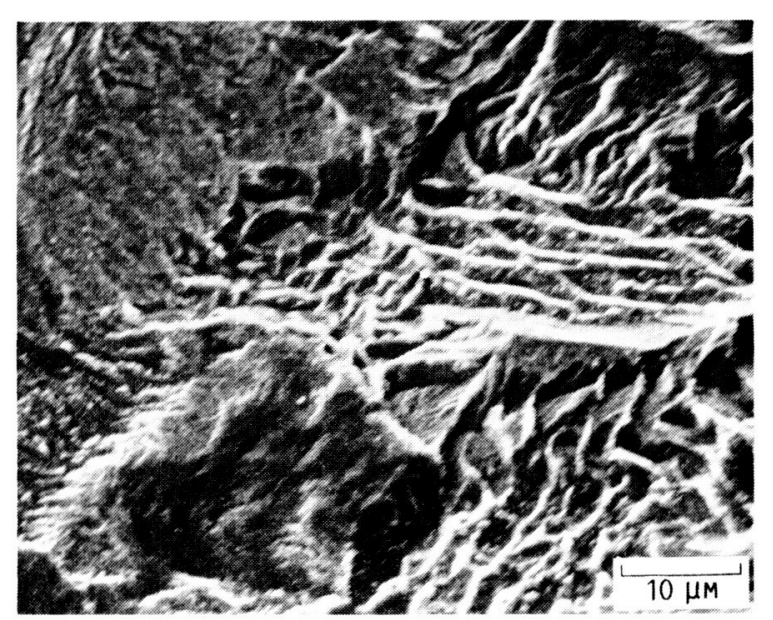

(B) FRACTURE SURFACE.

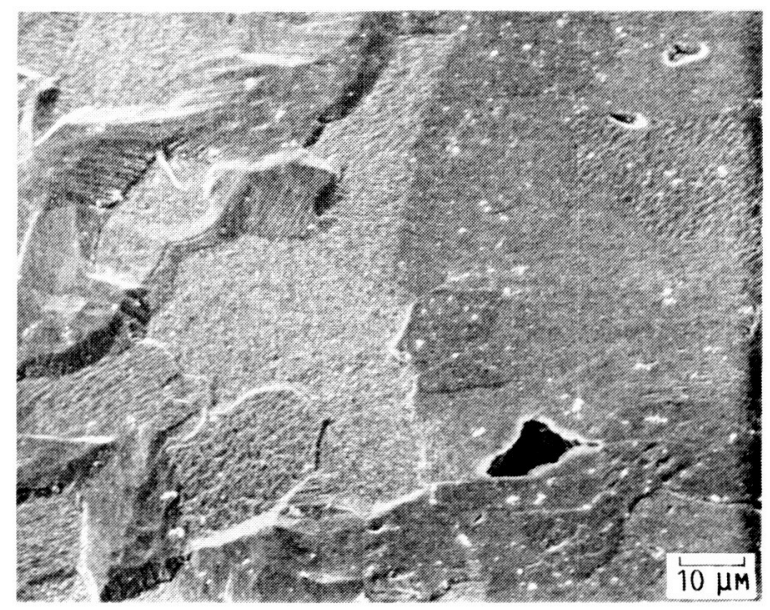

(D) REGION OUTSIDE WEAR AREA AND SMOOTH WEAR AREA.

FIGURE 6. - AN OPTICAL PHOTOMICROGRAPH AND SCANNING ELECTRON PHOTOMICROGRAPHS OF A WEAR SCAR AND SURROUNDINGS ON IRON IN $12.1 \mathrm{~N}$ HYDROCHLORIC ACID. 

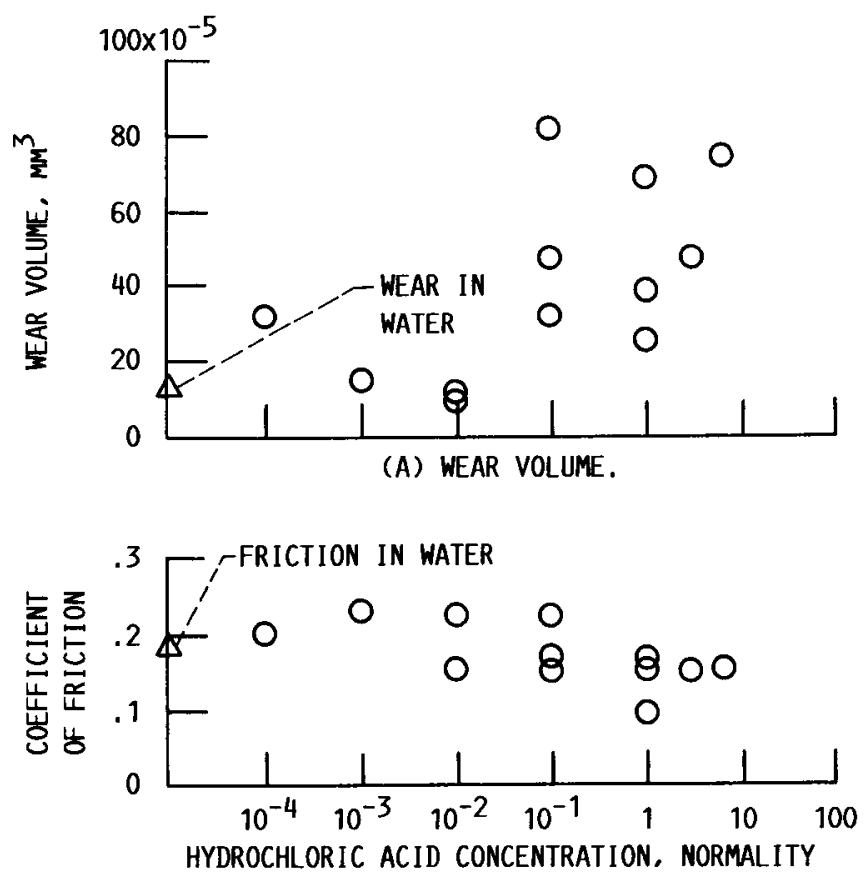

(B) COEFFICIENT OF FRICTION

FIGURE 7. - WEAR AND COEFFICIENT OF FRICTION FOR NICKEL AS FUNCTION OF HYDROCHLORIC ACID CONCENTRATION. 


\section{DRIGINAL PAGE IS \\ DE POOR NIATITY}

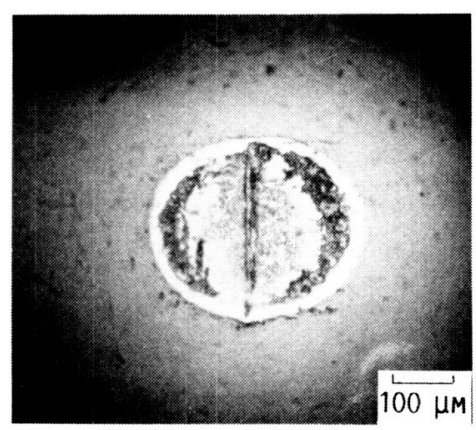

(A) WEAR SCAR.

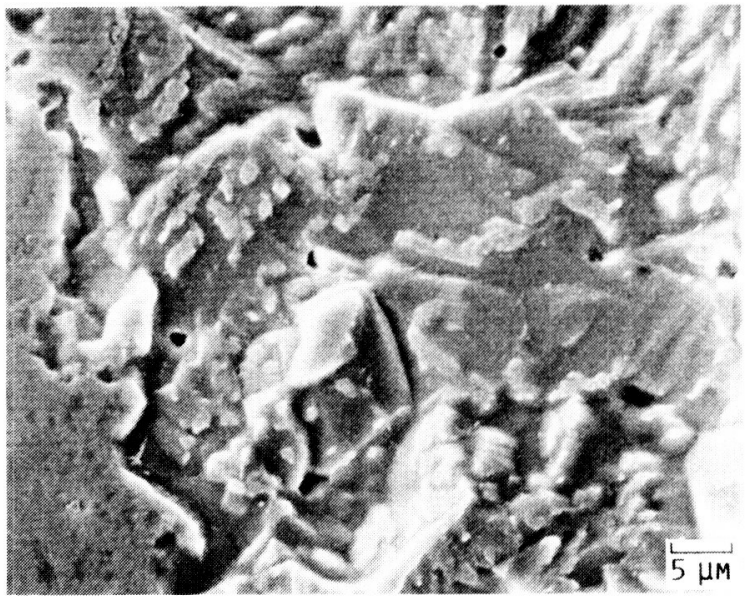

(B) PLASTICALLY DEFORMED AREA AND CORRODED AREA.

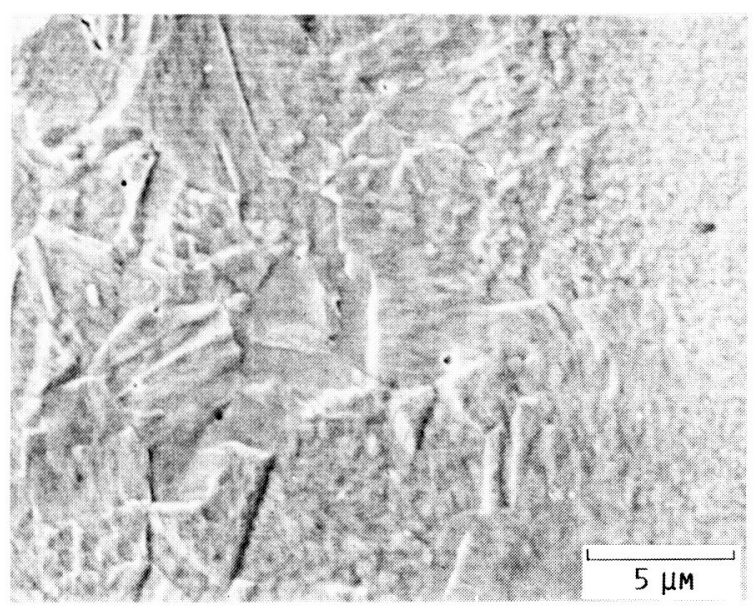

(C) CORRODED AREA.

FIGURE 8. - AN OPTICAL PHOTOMICROGRAPH AND SCANNING ELECTRON PHOTOMICROGRAPHS OF A WEAR SCAR ON NICKEL IN $0.1 \mathrm{~N}$ HYDROCHLORIC ACID. 


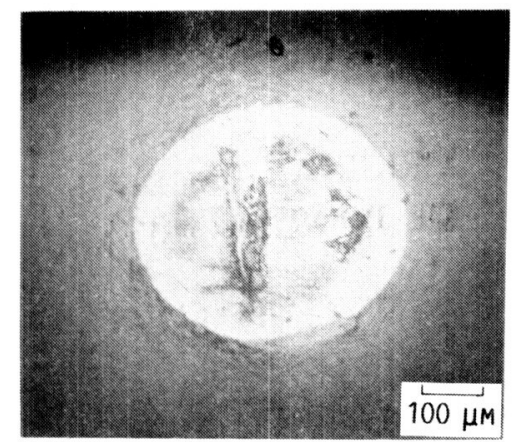

(A) WEAR SCAR.

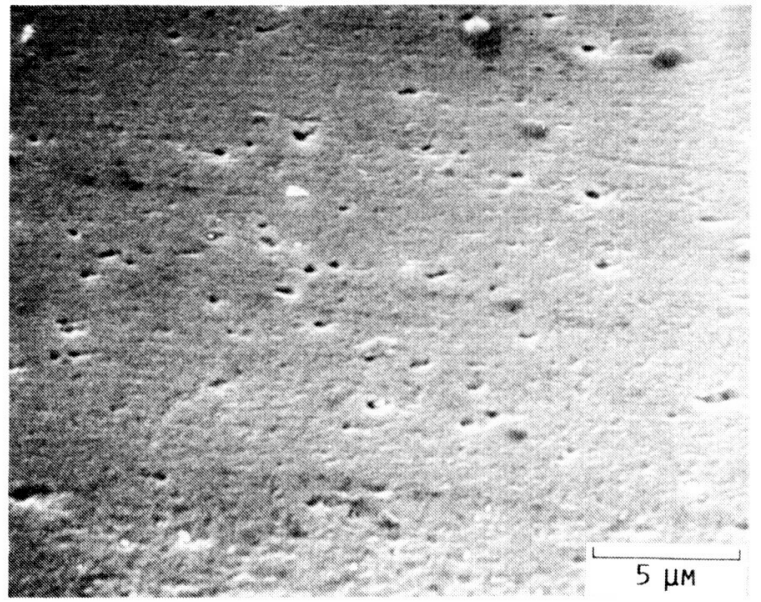

(B) PLASTICALLY DEFORMED WEAR SURFACE.

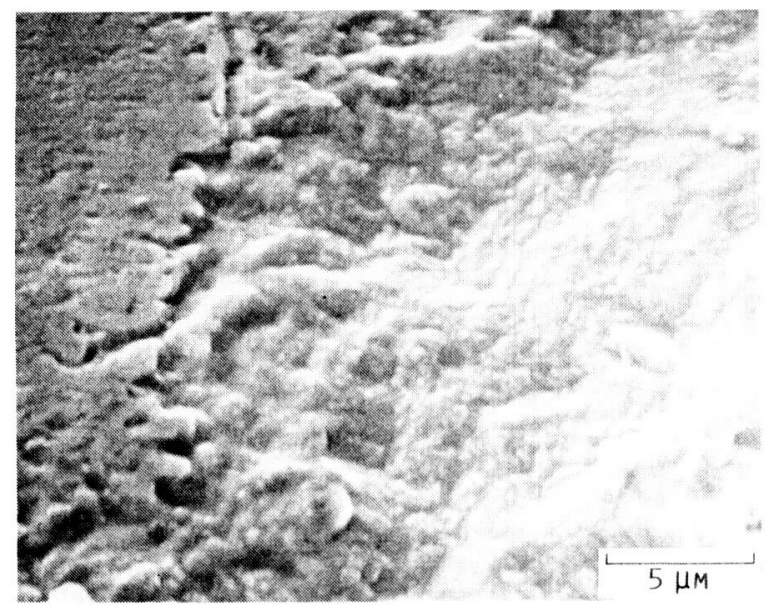

(D) SEVERE WEAR DAMAGE.

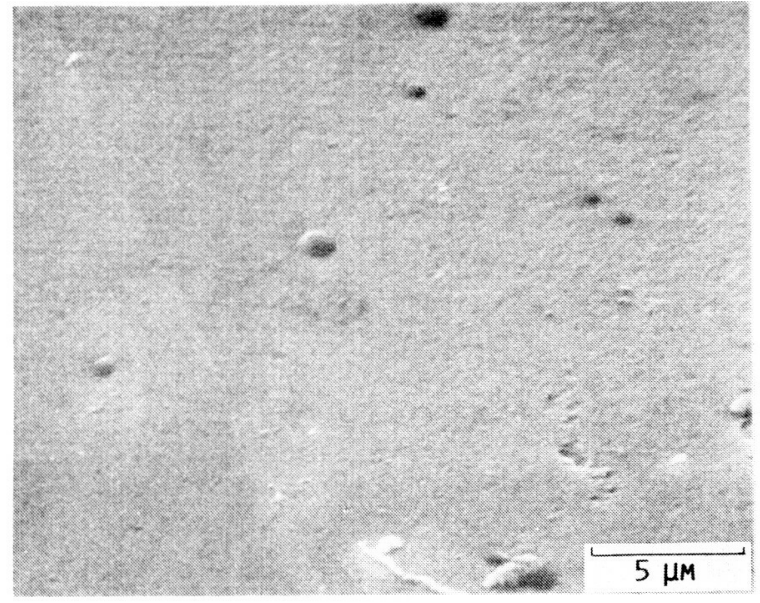

(C) EXTREMELY SMOOTH WEAR SURFACE.

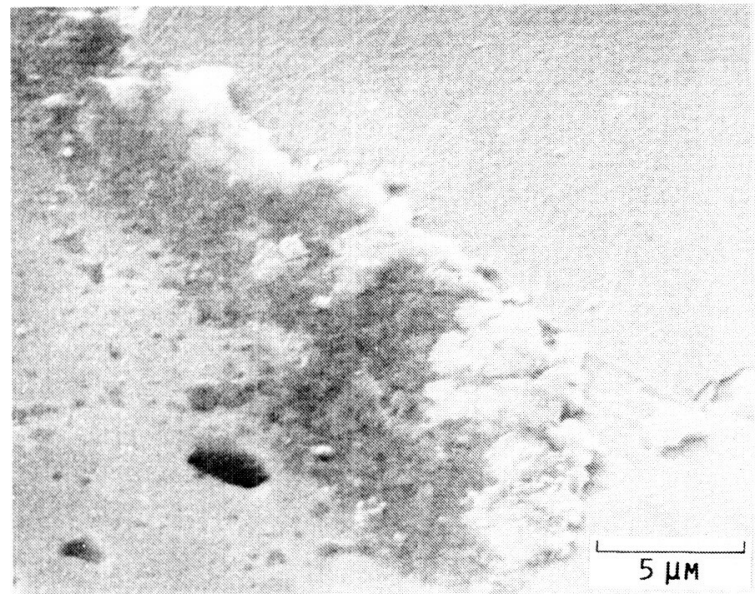

(E) WEAR DEBRIS.

FIGURE 9. - AN OPTICAL PHOTOMICROGRAPH AND SCANNING ELECTRON PHOTOMICROGRAPHS OF A WEAR SCAR AND SURROUNDINGS ON NICKEL IN $0.1 \mathrm{~N}$ HYDROCHLORIC ACID. 


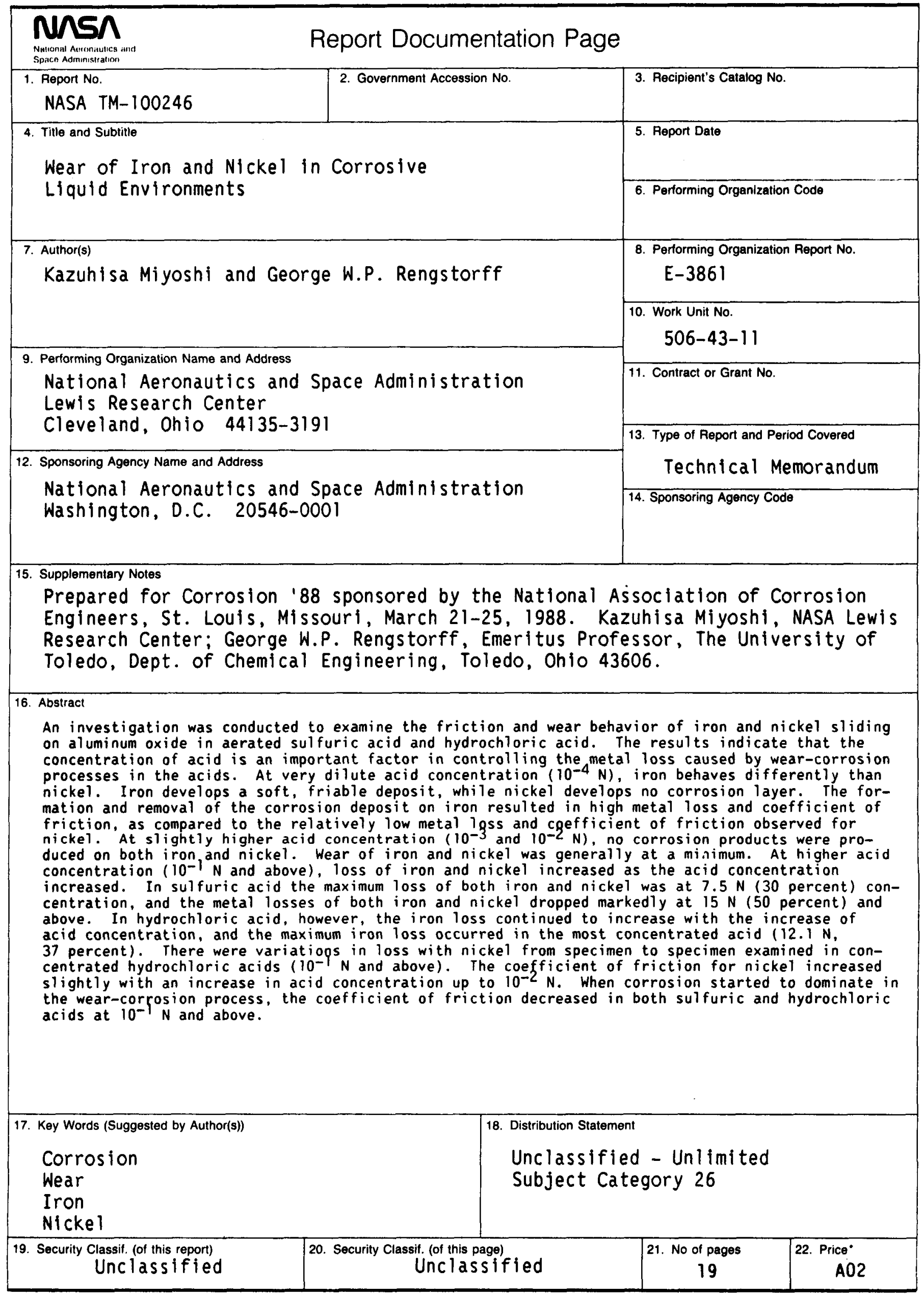

